\title{
Valoración médico-laboral del trabajador con Síndrome de Sjögren
}

\section{Medical-laboral valoration for workers with sjögren syndrom}

\section{Maider Usarbarrena Ekiza}

Inspección médica del INSS - Navarra

Recibido: 09-01-14

Aceptado: 11-03-14

\section{Correspondencia}

Maider Usarbarrena Ekiza

Instituto Nacional de la Seguridad Social

Avda. Baja Navarra n. ${ }^{\circ} 10$

31003 - Pamplona (Navarra)

Correo electrónico: maider.usarbarrena@seg-social.es

\section{Resumen}

El Síndrome de Sjögren (SS) es una patología inflamatoria crónica, infradiagnosticada y de etiología desconocida, que se caracteriza por la infiltración linfocitaria de las glándulas exocrinas. La sintomatología puede ser muy variada. Inicialmente, lo más común es que se presente sequedad de mucosas (principalmente oculares y bucales); también se puede asociar a otras enfermedades autoinmunes, y hasta en el $65 \%$ de los casos, se pueden presentar manifestaciones extraglandulares, pudiéndose afectar cualquier parte del organismo.

En muchos casos, la sintomatología inicial es leve, achacándose habitualmente a un posible disconfort en el puesto de trabajo.

A esto hay que añadir que a nivel laboral no existe literatura específica en la que poder basarse para realizar una adecuada valoración médico-laboral.

El objetivo de este trabajo ha sido crear una herramienta que englobe, por una parte, la vigilancia de la salud específica, y por otra, definir (aunque sea de forma orientativa), los criterios para poder realizar una correcta valoración de la capacidad laboral en los trabajadores con Síndrome de Sjögren.

Palabras clave: Sjögren, síndrome, protocolo vigilancia sanitaria específico, valoración, capacidad, capacidad laboral, criterios de valoración, sequedad, glándula.

Med Segur Trab (Internet) 2014; 60 (234) 108-132

Abstract

The Sjögren Syndrom is a chronic inflammatory pathology, which is underdiagnosed and its etiology is unknown, it is characterized by a lymphocyte infiltration of the exocrine glands. The symptomatology, could be very varied. At first, the most common symptom is mucous dryness (mainly ocular and oral); it may also be associated to other autoimmune diseases, and in up to $65 \%$ of cases, extraglandular manifestations may appear affectting any part of the body.

The initial symptoms use to be mild, very often the cause seems to be a possible discomfort at workplace.

There is not a specific literature about an appropiate medical-laboral valoration in these kind of cases. 
The main objective of this work is to develop a tool for carrying out the specific health surveillance and to define the criteria for doing a right work capacity valoration.

Key words: Sjögren, Syndrom, specific health surveillance protocol, valoration, capacity, work capacity, valoration criteria, dryness, gland.

Med Segur Trab (Internet) 2014; 60 (234) 108-132 


\section{INTRODUCCIÓN}

El Síndrome de Sjögren (SS) es una enfermedad inflamatoria crónica, inicialmente considerada rara, pero que a posteriori se ha visto que su frecuencia sería mucho mayor, de no ser porque está infradiagnosticada; su sintomatología inicial, en muchos casos de carácter leve, hace que en numerosas ocasiones el paciente vaya de consulta en consulta de distintos especialistas hasta que por fin se le diagnostique.

A nivel laboral, tampoco hay literatura específica sobre este tema; la literatura existente que podría incidir en la principal sintomatología del SS primario, está orientada hacia técnicos de prevención en relación a problemas higiénico-ergonómicos del puesto de trabajo, que generen disconfort; sin embargo, el hecho de su no siempre fácil diagnóstico, hace que también a nivel laboral sea infravalorada. Estudios en relación al Síndrome del Edificio Enfermo, o por ej. las numerosas indicaciones de pautas higiénicas en casos de fatiga visual etc, hacen que la sintomatología que aquejan estos pacientes se aísle en vez de tenerla en cuenta de una manera global, aumentando así la dificultad de diagnóstico de este síndrome (principalmente en el inicio del cuadro).

Dada la falta de estudios específicos, se ha considerado de importancia el poder disponer de un instrumento de trabajo que pueda emplearse en los pacientes afectos de SS, principalmente para poder realizar una correcta valoración médico-laboral.

\section{OBJETIVOS}

\section{Objetivo principal}

El objetivo principal de este trabajo es el de crear un protocolo de vigilancia sanitaria específica para el Síndrome de Sjögren, que pueda utilizarse como herramienta de trabajo, cara a solventar las necesidades que los trabajadores con SS puedan presentar a nivel laboral.

\section{Objetivos secundarios}

Se han planteado los siguientes objetivos secundarios:

1. Realizar una actualización médica del Síndrome de Sjögren, con la que poder desarrollar a posteriori el resto de objetivos planteados.

2. Definir unos criterios funcionales específicos de valoración de la capacidad laboral del paciente con Síndrome de Sjögren.

\section{Fuentes, material y métodos}

Para la actualización médica, se ha empleado la literatura médica existente sobre el SS, tanto páginas web, como publicaciones de revistas y libros, tal y como se especifica posteriormente en la bibliografía.

En relación al protocolo de vigilancia sanitaria específico, dada la falta de bibliografía sobre el tema, se ha intentado solventar mediante la creación de una herramienta con la que poder realizar, de una manera sencilla, una valoración médico-laboral en los trabajadores con SS; formando parte de dicho protocolo se han tenido en cuenta los criterios de valoración de la capacidad laboral y un protocolo de vigilancia de la salud específico en el SS. 


\section{RESULTADOS}

\section{Actualización médica en el Síndrome de Sjögren}

\section{Definición}

El Síndrome de Sjögren (SS) es una enfermedad inflamatoria crónica de etiología desconocida, de progresión lenta, que se caracteriza por la infiltración linfocitaria de las glándulas exocrinas ${ }^{1}$.

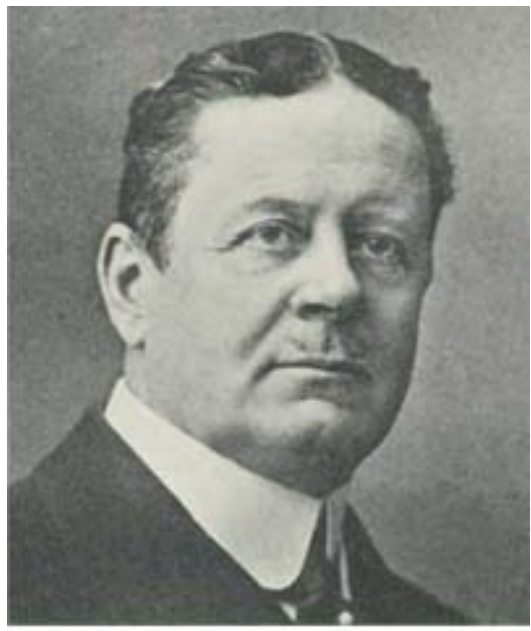

H. Sjögren (1856-1922)

Fue descrita en 1930 por el oftalmólogo sueco Henrik Samuel Conrad Sjögren (de ahí su nombre), y se caracteriza por sequedad, fundamentalmente de ojos (xeroftalmia) y boca (xerostomía), debido a una disminución de la secreción glandular lagrimal y salivar; sin embargo, se ha visto que un tercio de los enfermos presentan inicialmente manifestaciones extraglandulares sistémicas ${ }^{2}$.

El SS puede ser primario o secundario:

a. El SS primario es el que aparece aislado, sin la presencia de otra enfermedad autoinmune asociada, y se define por la asociación de queratoconjuntivitis seca y xerostomía.

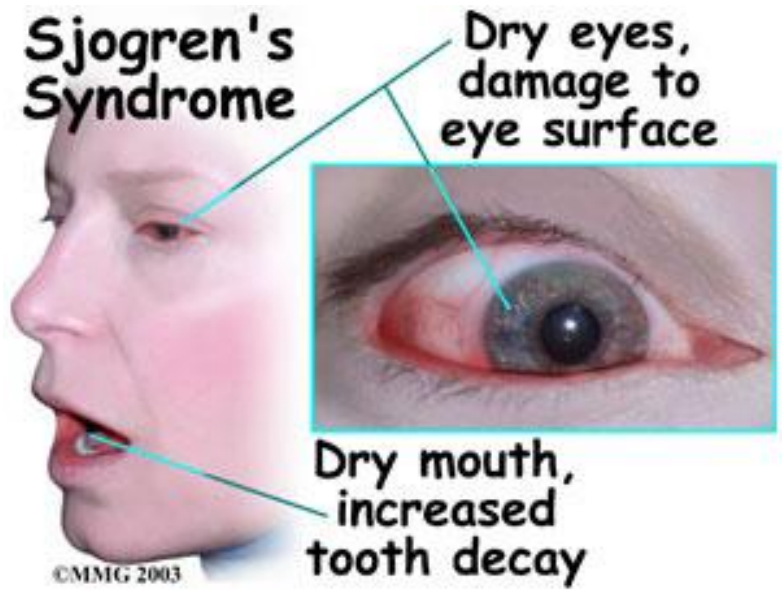

b. El SS secundario es el que se asocia a otras enfermedades autoinmunes, las más frecuentes son la Artritis Reumatoide (AR), el Lupus Eritematoso Sistémico (LES), 
esclerodermia (ES), dermatomiositis, tiroiditis y cirrosis biliar primaria, entre otras.

\section{Incidencia y prevalencia}

Predomina en mujeres $(9: 1)^{1}$, puede aparecer a cualquier edad, aunque es más frecuente que se manifieste entre la cuarta y quinta décadas de la vida.

Se desconoce la incidencia y prevalencia de esta enfermedad, pero es muy frecuente, ya que además del SS primario, un 30\% de los pacientes afectos de AR, LES y ES padecen un SS secundario ${ }^{2}$. Desde la Sociedad Española de Reumatología ${ }^{3}$ estiman que puede llegar a afectar al 3\% de la población; sin embargo, se piensa que el porcentaje es mucho mayor, ya que, como apuntan en la Asociación Española de Síndrome de Sjögren (AeSS) ${ }^{4}$, a pesar de que estudios han demostrado una incidencia aproximada del $2 \%$ en la población general, en España no se puede extrapolar, debido a la ausencia de estudios epidemiológicos (puesto que no todos los pacientes con sintomatología han sido diagnosticados, ya que en numerosos casos, tras la aparición de los primeros síntomas, se tarda mucho tiempo hasta conseguir el diagnóstico).

La incidencia, así mismo, varía mucho dependiendo del país, e incluso dentro de un mismo país, también se observan diferencias importantes entre distintas comunidades (posiblemente por falta de una buena coordinación del equipo multidisciplinar, una vez que el paciente comienza con la sintomatología).

\section{Etiopatogenia}

No se conoce la etiología de la enfermedad. Se han descrito algunos posibles desencadenantes $^{3}$, que pueden deberse a la infección de algunos virus y/o retrovirus o causas hormonales (estrógenos, déficit androgénico), los cuales darían lugar al SS, en sujetos genéticamente susceptibles a una respuesta inadecuada frente a ciertos componentes del epitelio glandular exocrino (como las ribonucleoproteínas Ro y La).

Los antígenos pueden estimular la respuesta inmune del sistema glandular exocrino (epitilitis autoinmune) mediante una infiltración inflamatoria a expensas principalmente de los linfocitos T activados, con predominio de CD4. A nivel local se produce IFN- $\gamma$, que podría inducir la expresión de moléculas de clase II en las células epiteliales, y actuar como presentadoras de antígenos. Se produce una activación de los linfocitos B, mediada por linfocitos $\mathrm{T}$ y macrófagos; la hiperestimulación de estos linfocitos $\mathrm{B}$, hace que se produzcan numerosos autoanticuerpos y junto con la producción local de distintas citocinas, hace que se perpetúe la respuesta inflamatoria en las glándulas salivales. El exceso de activación linfocítica $B$ sería el responsable de las manifestaciones extraglandulares.

Estudios inmunogenéticos ${ }^{1,5}$ han establecido una mayor predisposición de Síndrome Sjögren primario en los haplotipos HLA-B8, HLA-DR3 y HLA-DRw52, así como HLADQA1 y HLA-DQB1.

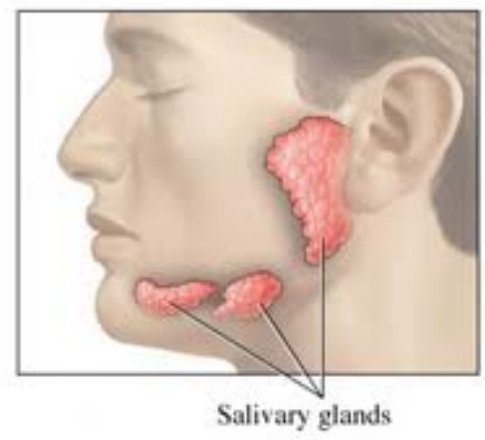




\section{Sintomatología y complicaciones}

La sintomatología más frecuente es la debida a la hipofunción y/o atrofia glandular. Los síntomas más frecuentes son los siguientes ${ }^{1,2,3,6}$ :

\section{Manifestaciones glandulares}

1. Síntomas oculares: La inflamación de las glándulas lagrimales disminuye la secreción de lágrimas, produciéndose xeroftalmia; ésta está presente en la mayoría de los pacientes con SS primario; las principal sintomatología:

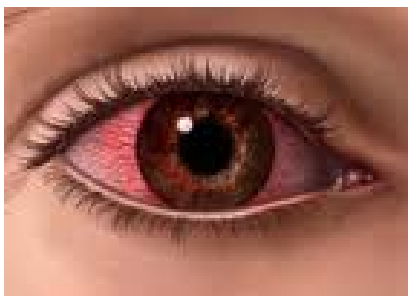

a. Sensación de cuerpo extraño ocular, sensación de arenilla en los ojos

b. Abundantes legañas matutinas y con frecuencia, ojos enrojecidos.

c. Ardor en los ojos, fotofobia

d. Aumento de la fatiga ocular (debido a la disminución del tiempo de ruptura de la lágrima y a la disminución de la secreción lagrimal).

Como complicación cabe destacar la conjuntivitis y queratitis filamentosa (dolor ocular, quemazón, sensación de cuerpo extraño), pudiendo llegar a producirse úlceras corneales.

2. Síntomas de la boca y garganta: con la pérdida de glándulas salivares, los síntomas son los derivados de la disminución salivar, produciéndose la xerostomía o hiposialia, cuya sintomatología es la siguiente:

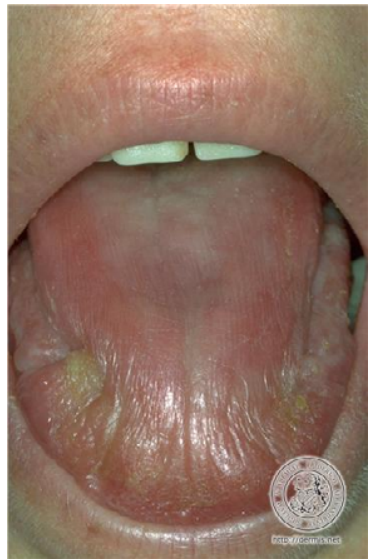

a. Boca seca, mucosa apergaminada, precisa beber agua en abundancia.

b. Dificultad para hablar, masticar y deglutir, principalmente alimentos sólidos y/o secos.

c. Disminución del gusto o disgeusia (alteraciones en el sentido del gusto) por alteraciones en la mucosa lingual (fisuras, pérdida de papilas gustativas...). 

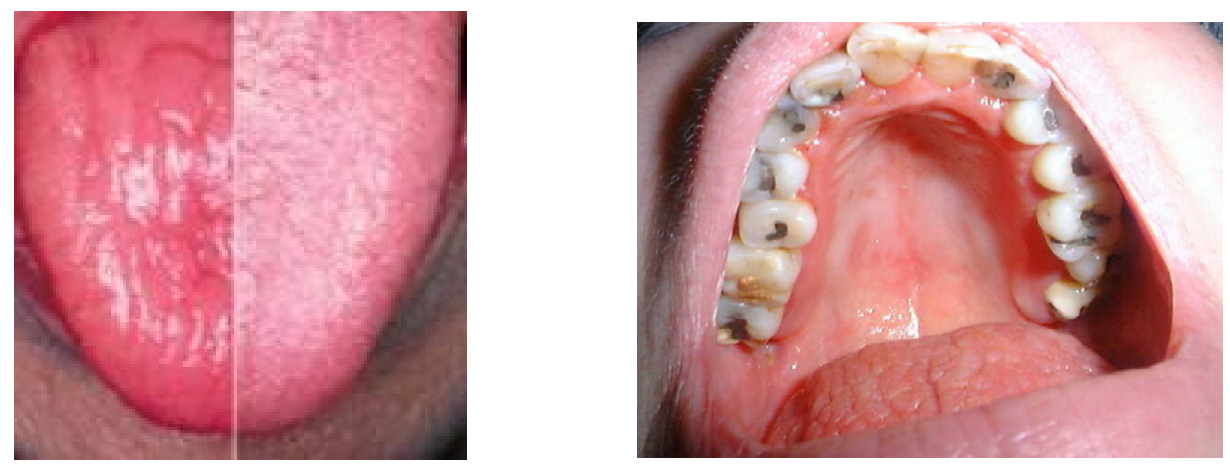

Como complicaciones, se pueden citar las úlceras bucales, queilitis angular, en ocasiones dolor, candidiasis y aumento de las caries (y la consiguiente pérdida precoz de piezas dentales), porque al disminuir la secreción salivar, disminuye también el efecto bactericida de ésta. La complicación más importante es el linfoma no Hodgkin.

3. Tumefacción parotídea o hipertrofia parotídea: es una manifestación frecuente pero no siempre presente, aunque es posible que haya algún episodio de tumefacción de las glándulas salivares mayores.

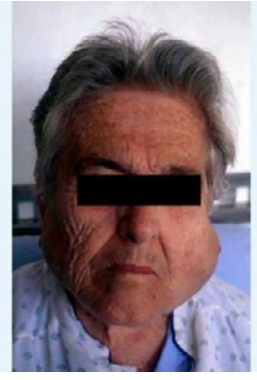

La existencia de esta sintomatología obliga a descartar linfoma.

4. Otros síntomas debido a otras xerosis:

a. Dispareunia: En las mujeres, el mal funcionamiento de las glándulas de la vagina hace que las paredes vaginales estén secas y es frecuente que las pacientes con síndrome de Sjögren tengan dolor durante las relaciones sexuales derivado de la sequedad vaginal.

b. Xerodermia.

c. Sequedad nasofaríngea: puede provocar ulceraciones e incluso perforación del tabique nasal.

\section{Manifestaciones extraglandulares:}

Están presentes hasta en el $65 \%$ de los casos; en estos casos es más frecuente encontrar autoanticuerpos positivos. Se puede afectar cualquier parte del organismo (intestino, bronquios-pulmones, glándula tiroides, piel, músculos, riñones o el sistema nervioso).

1. Afectación osteomuscular: es la sintomatología más frecuente, con artralgias, principalmente de pequeñas articulaciones (generalmente en las manos), aunque no está bien establecida la existencia de una artropatía específica.

2. Astenia y fatiga: el cansancio es un síntoma frecuente y molesto, como en otras enfermedades reumáticas. Hasta un $25 \%$ pueden llegar a tener rasgos de fibromialgia. 
3. Distintas manifestaciones neuropsiquiátricas como cuadros depresivos y/o ansiosos, trastornos de la conducta, alteraciones de memoria, trastornos del sueño. Son manifestaciones frecuentes.

4. Afectación cutánea: puede observarse un fenómeno de Raynaud, lesiones "lupus like”, vasculitis cutánea y/o púrpura de miembros inferiores (que puede asociarse en este último caso a crioglobulinemia e hipergammaglobulinemia).

5. Puede haber vasculitis sistémica, asociada a la presencia de crioglobulinemia, aunque suele ser infrecuente. En el caso de la crioglobulinemia (crioglobulinas tipo $\mathrm{II}^{7}$ ), son crioglobulinas mixtas que tienen dos componentes de inmunoglobulinas, uno monoclonal (habitualmente IgG y menos frecuente el IgM) y el otro policlonal; interaccionan y se produce el crioprecipitado con las bajas temperaturas (generalmente se vuelven a disolver a $37^{\circ} \mathrm{C}$ ).

6. Afectación respiratoria: la tos seca es un síntoma característico de la afección glandular de vías respiratorias. Son frecuentes las infecciones respiratorias por la disminución de la secreción bronquial. Puede haber afectación intersticial hasta en una cuarta parte de pacientes (sobre todo en aquellos pacientes con ANA+) y/o fibrosis pulmonar, asintomáticos en muchas ocasiones, hasta que se detecta por la disnea progresiva en fases tardías. También pueden darse: rinitis atrófica, xerotráquea, hiperreactividad bronquial y pseudolinfoma.

7. Afectación neurológica: El espectro de manifestaciones neurológicas en el SS es muy amplio e incluye desde formas asintomáticas (lesiones desmielinizantes en sustancia blanca) hasta formas de afectación focal o difusa cerebral, de médula espinal o epilepsia ${ }^{8}$. Puede haber polineuritis, mononeuritis múltiple, afección de pares craneales (fundamentalmente neuralgia del trigémino), crisis comiciales, síndromes migrañosos...Aunque de manera excepcional, puede haber afectación del sistema nervioso central como meningitis aséptica o encefalitis; también puede haber afectación del sistema nervioso autónomo.

8. Afectación digestiva: estreñimiento (por la sequedad intestinal), disfagia, gastritis crónica atrófica, asociación a enfermedad celíaca, insuficiencia pancreática exocrina (pancreatitis autoinmune). Puede haber afectación hepática con hipertransaminemia moderada y/o asociación con cirrosis biliar primaria (más del 5\% con anticuerpos antimitocondriales).

9. Afectación nefrológica: puede haber afectación renal, fundamentalmente por afectación tubular que cursa con acidosis tubular renal, urocosuria y fosfaturia y se suele asociar a nefritis tubulointersticial; en ocasiones hay nefrocalcinosis o glomerulonefritis (es extremadamente rara y suele ocurrir en pacientes con vasculitis sistémica, crioglobulinemia o LES); los casos que cursen con acidosis tubular, pueden complicarse con litiasis, osteomalacia o hipopotasemia crónica.

10. Afectación cardíaca: aunque de manera muy infrecuente, puede haber pericarditis subclínica.

11. Afectación tiroidea: puede haber algún tipo de disfunción tiroidea, lo más frecuente son las tiroiditis autoinmunes (hasta en un $15 \%$, sobre todo en mujeres).

12. Hay una mayor predisposición a sufrir linfomas no Hodgkin (LNH) tipo B, con fenotipo IgM (el riesgo puede ser del 5\%, muy superior al de la población general), principalmente en parótida, pulmón o tubo digestivo; hay que sospechar la evolución hacia linfoma en aquellos casos en los que aparece parotidomegalia, esplenomegalia, púrpura, anemia, disminución de la hipergammaglobulinemia, descenso del complemento $\mathrm{C} 4$, negativización del factor reumatoide o aparición de una banda monoclonal en el proteinograma. Se trata de la causa de muerte en la quinta parte de los pacientes con SS primario. La prevalencia de anti-Ro y anti-La + es mayor.

Para el diagnóstico del LNH hay numerosas clasificaciones ${ }^{9}$, pero en la actualidad se utiliza la clasificación Real-WHO; no obstante, a nivel de estadiaje clínico, sigue siendo de utilidad la clasificación del estadiaje de Ann Arbor: 


\section{Clasificación por Estadios de ANN-ARBOR 1971. Modificación de COSTWOLDS para la EH 1989}

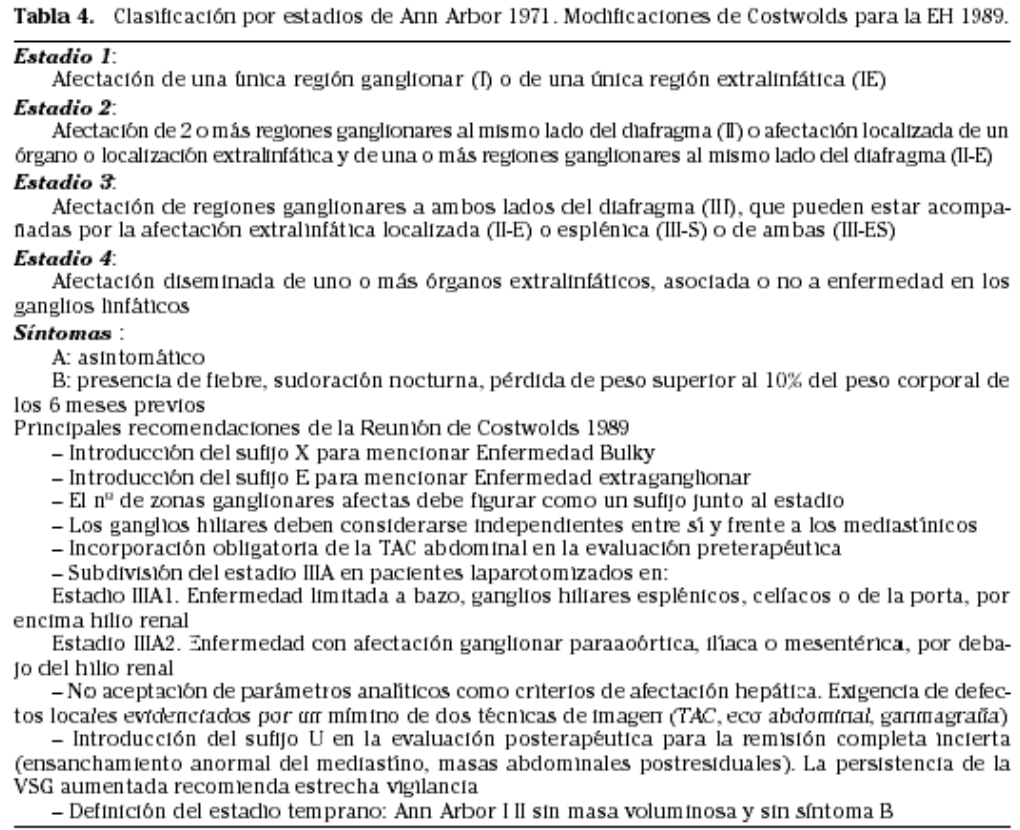

\section{Pronóstico}

La sintomatología en el Síndrome de Sjögren se debe a la hipofunción y/o atrofia glandular; en general el pronóstico es benigno, salvo en los casos en los que existe afectación visceral (SS secundario), que estará en relación con la enfermedad asociada; por ello, la evolución clínica no es predecible, aunque la mayoría suelen seguir un curso estable de varios años de evolución con los mismos síntomas.

En el caso de que se complique con un $\mathrm{LNH}^{9}$, independientemente de la clasificación empleada, el pronóstico vendrá dado según unos factores pronósticos:

1. Edad: $>60$ años es desfavorable.

2. Estadio clínico de Ann Arbor: estadío III/IV son desfavorables.

3. Número de territorios extraganglionares afectados: $>2$ es desfavorable.

4. Estado general: malo es desfavorable.

5. La inmunodeficiencia es desfavorable.

6. Tasa de LDH: elevada es desfavorable.

7. Tasa de $\beta 2$ microglobulina: elevada es desfavorable.

8. La elevación del cobre plasmático: en relación directa con la masa tumoral global, así como con la actividad tumoral.

9. Peor pronóstico si aparecen niveles celulares elevados de determinadas enzimas del metabolismo púrico y pirimidínico (ADA, PNP, TP, TK) y expresión del antígeno 4F2 y anticuerpo monoclonal Ki-67.

10. Hay numerosas alteraciones citogenéticas que se pueden considerar como factores pronósticos.

11. Tipo de respuesta obtenida con tratamiento (completa RC o parcial RP) así como la rapidez en alcanzar la RC (más o menos de 4 ciclos), parecen tener una clara repercusión en el pronóstico de los pacientes. 


\section{FACTORES PRONÓSTICOS EN EL LNH}

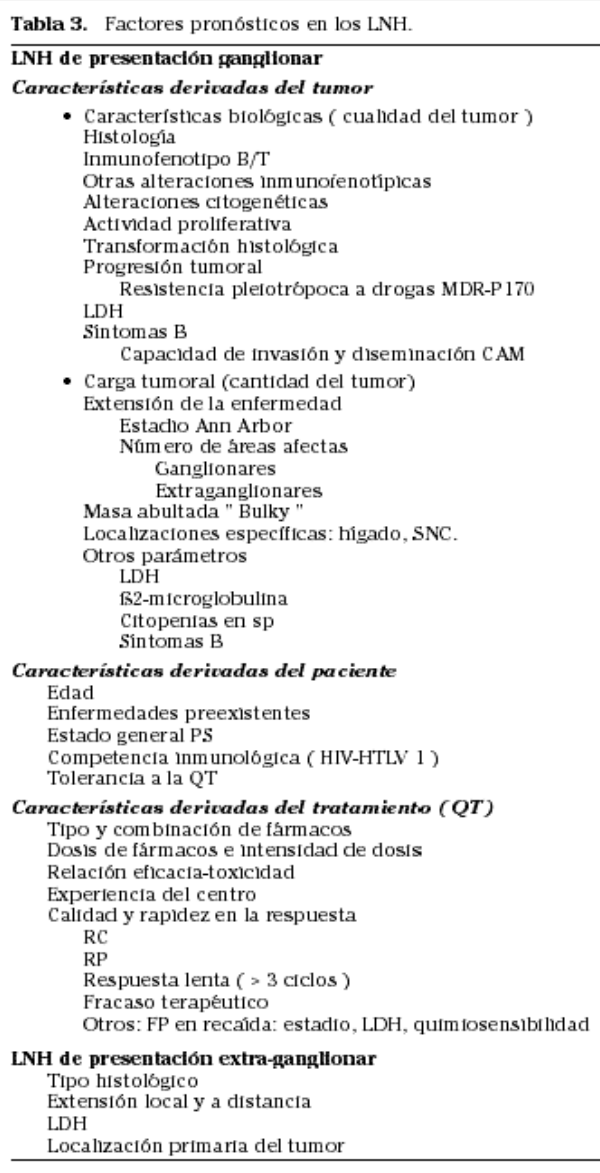

\section{Diagnóstico}

El diagnóstico se realiza inicialmente con una historia clínica detallada y exploración completa. Se añaden pruebas analíticas y otras pruebas específicas.

A diferencia de lo que ocurre en otras enfermedades sistémicas, no existe un consenso acerca de los criterios diagnósticos que definen al Síndrome de Sjögren ${ }^{1}$, pero resulta más fácil el diagnóstico si se siguen los Criterios diagnósticos establecidos por el grupo de Consenso Europeo para el estudio del Síndrome de Sjögren ${ }^{1,10}$.

a. Entrevista médica: encaminada a realizar una correcta anamnesis para valorar la sintomatología del paciente y realizar un primer diagnóstico diferencial.

b. Pruebas para el diagnóstico de ojo seco: El ojo seco se diagnostica mediante el Test de Schirmer y la tinción con rosa de Bengala o fluoresceína (y examen posterior con lámpara de hendidura para valorar el estado de la córnea), para diagnosticar la presencia o no de queratoconjuntivitis seca. El Test de Schirmer se realiza mediante la introducción de un papel secante milimetrado en el fondo de saco conjuntival en ambos ojos, durante 5 minutos; después se retiran y se miden los milímetros que de humidificación lagrimal de los ojos. Cuando es inferior a $5 \mathrm{~mm}$ en ambos ojos, la prueba se considera anormal, con una sensibilidad del $53 \%$ y una especificidad del $75 \%{ }^{1}$. Se considera la prueba normal (-) cuando la humedad llega a $10 \mathrm{~mm}$ (límite normal a partir del cual se considera que no hay sequedad). 


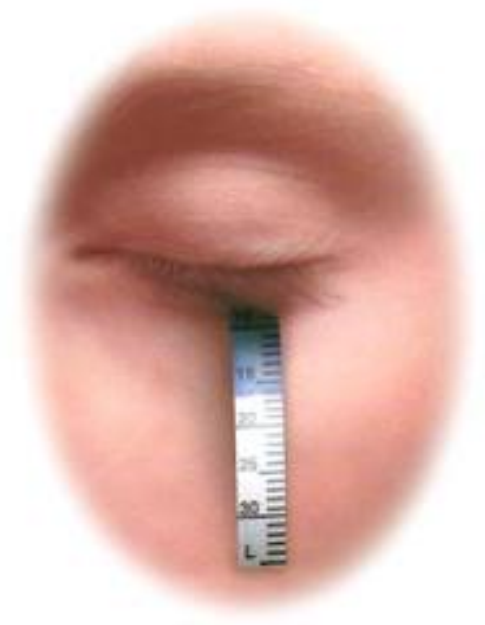

Entre 5 y $10 \mathrm{~mm}$ la sequedad es dudosa.

En los casos dudosos en los que la sequedad no haya sido diagnosticada por el Test de Schimer, es útil la tinción con fluoresceína o Rosa de Bengala, mediante las que, tras un análisis con la lámpara de hendidura, se valorará si existe o no queratoconjuntivitis punteada (característica de la sequedad crónica).

c. Pruebas para el diagnóstico de la xerostomía: La sequedad de la boca se pone en evidencia con la gammagrafía y/o sialografía de las glándulas salivales. Si estas pruebas no son concluyentes se realizará una biopsia de labio.

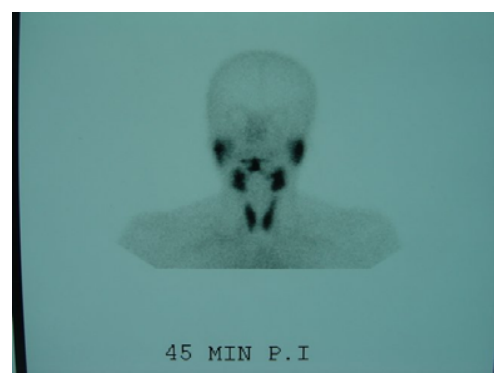

- La gammagrafía de glándulas salivales y parótida, consiste en la introducción intravenosa de un isótopo radioactivo (tecnecio 99, galio o indio), y se valora la captación y excreción del trazador (que en el caso del síndrome de Sjögren es mucho más lenta de lo normal), y en función de ambas características se clasifica en distintos grados:

- Grado 0: indica normalidad en la captación y excreción.

- Grado 1: cursa con retraso moderado en la incorporación con buena concentración.

- Grado 2: aparece retraso marcado en la incorporación y/o mala concentración con buena actividad oral.

- Grado 3: ausencia de visualización glandular con actividad oral variable.

- Grado 4: ausencia de visualización glandular con actividad oral débil o nula.

- La sialografía consiste en introducir un contraste en el conducto que lleva la saliva desde las glándulas salivales mayores (parótidas, submandibulares) hasta la boca. Al realizar después una radiografía pueden verse alteraciones en el interior de las glándulas salivales. Se puede realizar para evidenciar ectasias glandulares difusas.

- La sialometría mide el flujo salival sin estimulación, éste debe ser mayor de $1,5 \mathrm{ml}$ en $15 \mathrm{~min}$ (hay distintos métodos para realizarla, pero es una prueba incómoda). 
- La biopsia de glándulas salivales menores, por ejemplo la contenida en mucosa labial, permite confirmar el diagnóstico (aunque a veces no es necesario realizarla), y demuestra acúmulos focales de infiltración linfocitaria (sialoadenitis linfocítica), hiperplasia ductal y atrofia acinar.

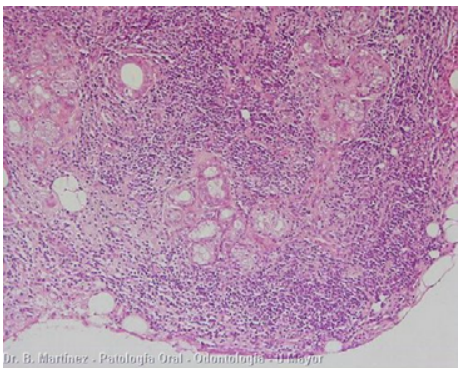

d. Pruebas de laboratorio: los datos de laboratorio son inespecíficos y no diagnósticos, pero será necesario una analítica para poder valorar si existe compromiso hematológico, hepático, pulmonar o renal; se debería realizar una analítica en la que se incluya hemograma (ver citopenias), bioquímica con reactantes de fase aguda, gasometría venosa (para descartar una posible acidosis), proteinograma completo y recuento de inmunoglobulinas, serologías virales (VHC, VIH, VEB) y autoinmunes. Estos últimos (los autoinmunes), son de especial utilidad: habrá que valorar anticuerpos antinucleares (ANA), factor reumatoide (FR), crioglobulinas, complemento, anticuerpos organoespecíficos (hígado, riñón, tiroides) y anticuerpos anti-Ro/SS-A y anti-La/SS-B, que son más específicos (aunque pueden verse en pacientes con LES).

Desde el año 2009 se ha propuesto la utilidad diagnóstica de los Anticuerpos Antialfafodrin (aAF) en pacientes con Anti-Ro negativos ${ }^{10}$. Estos anticuerpos se relacionan con inflamación glandular activa y una mejor respuesta al tratamiento con hidroxicloroquina, con incluso un aumento en la producción de lágrimas.

Se ha visto que la detección de péptidos de fibronectina en saliva podría ser un indicador de utilidad no invasivo ${ }^{11}$, y el medir la variación de sus niveles podría servir como un método de monitorización para valorar la evolución de la enfermedad.

Los pacientes con manifestaciones neurológicas con diagnóstico de SS, se vio a nivel experimental que tenían, en suero, valores estadísticamente inferiores de autoanticuerpos anti-hHesB en comparación con la población sana ${ }^{12}$. En ese mismo estudio, las proteínas anti-Tau no mostraron diferencias estadísticamente significativas. Esto se ha corroborado en algún estudio posterior ${ }^{12}$ y se ha visto que existe otro autoanticuerpos que puede ser de utilidad en el diagnóstico, concretamente el anti-hIscA, que también muestra valores inferiores en pacientes con SS que en los controles.

e. Anatomía patológica ${ }^{5}$ : dado que las dianas de la enfermedad son principalmente las glándulas salivares y lagrimales (aunque también pueden afectarse otras glándulas exocrinas como las que revisten aparato gastrointestinal, respiratorio y vagina), el primer hallazgo histológico será la infiltración periductal y perivascular de las glándulas salivares, tanto mayores como menores; a medida que va evolucionando la patología, la infiltración linfocitaria se hará masiva, pudiéndose encontrar folículos linfoides con centros germinales (en las glándulas salivares de mayor tamaño). 


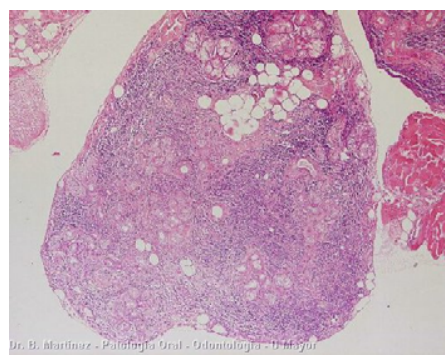

En los conductos, las células pueden mostrar hiperplasia y llegar a obstruir la luz del mismo. Posteriormente se podrá observar la atrofia de los acinos con fibrosis e hialinización, y en etapas más avanzadas de la enfermedad, atrofia con sustitución del parénquima por tejido adiposo.

A veces, el infiltrado linfocitario es tan extenso que parece un linfoma, pero se diferencia de éste por el aspecto benigno de los linfocitos, población heterogénea de células y conservación de la arquitectura lobulada de la glándula.

Antiguamente se denominaba Enfermedad de Mikulicz a la inflamación de las glándulas lagrimales y salivares; esta se puede dar en otras patologías como la sarcoidosis, leucemia, linfoma u otros tumores; por eso, para el diagnóstico del SS es esencial, en esos casos, el estudio de una biopsia de labio (para examinar las glándulas salivales menores); ésta se realiza mediante cirugía mínimamente invasiva tomando una muestra de tejido glandular para posterior análisis anatomopatológico. Después se prepara la muestra con tinción de hematoxilinaeosina, en la que se puede ver la infiltración linfocitaria local.

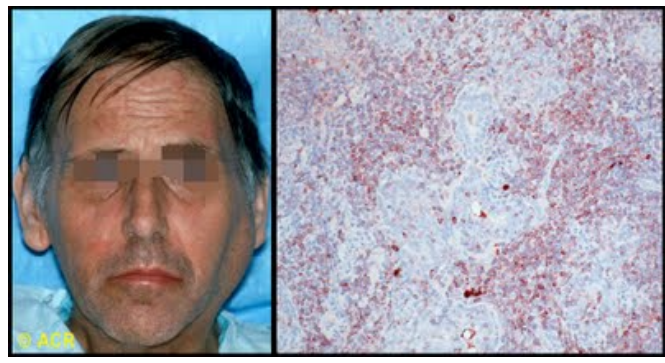

Los ganglios linfáticos de los pacientes con SS, además de estar aumentados, muestran una infiltración por células pleomórficas con mitosis frecuentes. En los estadíos iniciales, las células $\mathrm{B}$ que responden a varios autoantígenos, son policlonales. Es probable que la activación policlonal de las células B en el interior de las glándulas y de los ganglios cree el marco idóneo para la posterior aparición de una población neoplásica de células B monoclonales. Estos tumores se llaman linfomas de la zona germinal. Éste podría ser el origen del elevado riesgo (hasta un 40\% más) de que los pacientes con SS desarrollen una neoplasia linfoide maligna.

f. Otras pruebas: radiografía de tórax y/o Tomografía Computerizada de alta resolución en casos en los que se sospeche afectación pulmonar (imágenes de vidrio deslustrado, nódulos subpleurales, engrosamiento septal, bronquiectasias y atelectasias); biopsia de médula ósea o frotis de sangre periférica (si hay sospecha de síndrome linfoproliferativo); ecografía y Resonancia Magnética de glándulas salivales: pruebas no invasivas y con buenos resultados.

Se ha demostrado de utilidad el PET-TAC ${ }^{14}$ en aquellos casos en los que, sospechando afectación pulmonar, se deba hacer un diagnóstico diferencial (por ej. Afectación pulmonar tras diseminación de candidiasis oral vs afectación tumoral).

Para la valoración de la función pulmonar, además, será necesaria la realización de una espirometría +/- test de difusión (si se sospecha afectación restrictiva), pulsioximetría +/- gasometría, habrá que plantearse si puede ser de utilidad el Test de la Marcha... 
Si se sospecha afectación pericárdica, además de la clínica y auscultación, será necesario realizar ECG, analítica con enzimas cardíacas y ecocardiograma.

En el caso de sospecha de patología de nervio periférico, será imprescindible la valoración electroneurofisiológica mediante ENG-EMG, y según la región (pares craneales...) tal vez fuese necesaria la realización de potenciales evocados.

Desde los años 80 se han propuesto multitud de criterios de clasificación de este síndrome. Actualmente se aceptan los criterios europeoamericanos de 2002 ${ }^{15}$; según el grupo de Consenso Europeo para el estudio del Síndrome de Sjögren (GECUSS) ${ }^{1}$, para el diagnóstico de SS son necesarios 4 de los 6 criterios, siendo necesario que uno de ellos sea una biopsia de glándula salival positiva o bien Ac anti-Ro/La positivos.

Los criterios diagnósticos del síndrome de Sjögren (según GECUSS) son los siguientes:

* Se consideran criterios de exclusión: linfoma previo, sida, sarcoidosis o enfermedad del injerto contra huésped, VHC.

\section{Criterios diagnósticos de Síndrome de Siögren}

(Grupo de consenso europeo para el estudio del SS)

1. Síntomas oculares: una o más respuestas positivas.

a. ¿Ha tenido molestias diarias y persistentes de ojo seco durante más de 3 meses?

b. ¿Tiene o ha tenido sensación de arenilla en los ojos de forma recurrente?

c. ¿Usa lágrimas artificiales 3 o más veces al día?

2. Síntomas orales: una o más respuestas positivas.

a. ¿Ha tenido sensación de tener la boca seca de manera diaria, durante más de 3 meses?

b. ¿Ha tenido de forma persistente inflamación/tumefacción de alguna glándula salival en la edad adulta?

c. ¿Ingiere a menudo líquidos durante las comidas (sobre todo para tragar los alimentos secos)?

3. Signos oculares: resultado + de al menos una de las siguientes:

a. Prueba de Schimer ( $<5 \mathrm{~mm}$ en $5 \mathrm{~min})$.

b. Prueba Rosa de Bengala (<4 puntos según la clasificación de Van Bÿsterveld).

4. Hallazgos histopatológicos:

Uno o más focos en la biopsia de glándula salivar menor (el foco se define como un agregado de $\geq 50$ células mononucleadas, valorando el número de focos en $4 \mathrm{~mm}^{2}$ de tejido glandular).

\section{Compromiso objetivo de glandulas salivales.}

Resultado positivo de al menos una de las si siguientes pruebas:

1) Gammagrafía parotídea.

2) Sialografía parotídea.

3) Sialometría o flujo salival sin estimulación (< 1,5 ml en $15 \mathrm{~min})$.

\section{Autoanticuerpos.}

Positividad de al menos uno de los siguientes:

Anticuerpos contra los antígenos Ro (SS-A) o La (SS-B).

Anticuerpos antinucleares o ANA.

Factor Reumatoide (FR). 
Se acepta que existe un SS primario definido cuando están presentes como mínimo 4 de los 6 criterios.

Los criterios 1 a 3 están presentes con una respuesta afirmativa ( $a, b$ o c).

En 2009 se propuso la utilidad diagnóstica de los Anticuerpos Antialfafodrin (aAF) en pacientes con Anti-Ro negativos ${ }^{10}$.

\section{Diagnóstico diferencial}

Para realizar el diagnóstico diferencial ${ }^{2,6}$, habrá que tener en cuenta las principales manifestaciones clínicas: la queratoconjuntivitis seca o la xeroftalmia, la xerostomía y la artritis reumatoide $\mathrm{u}$ otros síndromes del tejido conectivo.

Múltiples factores, como la edad o la deshidratación, múltiples fármacos (antihistamínicos, antihipertensivos, diuréticos, miorrelajantes, psicofármacos) pueden ocasionar sequedad. Mediante distintas pruebas hay que realizar un cribado.

Determinadas enfermedades que hay que tener en cuenta a la hora de realizar el diagnóstico diferencial son: amiloidosis, enfermedad de injerto contra huésped, sarcoidosis, linfoma primario, infecciones virales (VEP, paperas, VHC, VIH...), alteraciones metabólicas.

En el caso de la xeroftalmia, el principal diagnóstico diferencial habrá que hacerlo con aquellas entidades en las que se presente inflamación ocular (por ej. en el Síndrome de Stevens-Johnson, penfigoide, conjuntivitis crónica, blefaritis crónica...), pueda tratarse de un proceso tóxico (por quemaduras o fármacos) o neurológicos (que cursen con alteración de la función de la glándula lacrimal o de la función palpebral); así mismo, también habrá que descartar otros procesos múltiples como traumatismos, hipovitaminosis A, anomalías del parpadeo, cicatrices palpebrales, anestesia corneal o irregularidad epitelial...

En relación a la xerostomía, hay que diferenciar ciertas infecciones víricas, determinados fármacos, que se trate de un síntoma psicológico, derivado de un tratamiento previo con radioterapia, patología endocrinológica como la diabetes mellitus, traumatismos...

En los casos que cursan con hipertrofia parotídea bilateral, el diagnóstico diferencial hay que hacerlo con infecciones víricas (parotiditis, gripe, Epstein-Barr, Coxackie A, Citomegalovirus, VIH...), sarcoidosis, amiloidosis, diabetes mellitus, hiperlipoproteinemia, pancreatitis crónica, cirrosis hepática, trastornos de la alimentación, acromegalia, hipofunción gonadal...

El VIH puede cursar con un síndrome seco, que se diferencia del sS porque predomina en varones jóvenes (el SS predomina en mujeres de edad intermedia) y por la ausencia de autoanticuerpos contra Ro/SSA y/o La/SSB (sí que puede haber presencia de ellos en el SS), infiltrados linfocitarios en las glándulas salivales con predominio de células CD8 (en el SS el infiltrado linfocitario de glándulas salivares suele se de CD4), asociado a HLA-DR5 (en el SS hay una asociación de manera más frecuente a HLA-DR3 y DRW52) y con pruebas serológicas positivas para VIH (en el SS normalmente son negativas).

\section{Tratamiento $^{2,10}$}

El SS es una enfermedad sistémica e incurable. El tratamiento depende de la severidad de los síntomas y lo que se pretende, principalmente, es aliviarlos y prevenir posibles complicaciones. Incluye 3 aspectos fundamentales:

1. Reponer de manera externa la pérdida de humedad.

2. Estimular la secreción glandular (mediante sustancias secretagogas).

3. Actuar farmacológicamente sobre el mecanismo que produce el SS. 
En la medida de lo posible, se deben evitar los diuréticos, antihipertensivos, anticolinérgicos, antihistamínicos y antidepresivos, porque agravan la hipofunción glandular lagrimal y salival.

Se deben evitar ambientes secos, aumentar la ingesta de agua y de alimentos que estimulen la secreción salival (alimentos ácidos sin azúcar) y mantener una adecuada higiene dental.

a. Tratamiento de la xerosis bucal.

El objetivo del tratamiento de la sequedad oral es el de estimular el flujo salival, para prevenir las complicaciones (caries, halitosis, cálculos y disfagia); la estimulación del flujo salival existente se consigue mediante sustancias secretagogas bien naturales (por ej. Caramelos o chicles sin azúcar, trozos de fruta, sustancias ácidas) o químicas, como el clorhidrato de pilocarpina (agonista muscarínico que, aunque puede ser beneficioso en ese aspecto, tiene efectos secundarios desagradables), cevimelina (no comercializada en Europa), bromhexina (estas tres están contraindicadas en pacientes con asma o glaucoma) o el interferon alfa (también con efectos secundarios).

También se puede reemplazar las secreciones orales mediante la toma frecuente de pequeños sorbos de agua o el empleo de alguno de las múltiples preparaciones de saliva artificial (tiene distinta viscosidad que la saliva natural, por lo que puede que eso condicione su uso por la susceptibilidad individual al producto).

En ocasiones pueden ser útiles, el uso de cápsulas con gel de vitamina $\mathrm{E}$ (mordiendo una cápsula por la noche y después enjuagando los dientes con el gel con el fin de mantener la humedad durante las horas de la noche).

Se debe incidir en que se realice un cuidado dental meticuloso, en el que se incluyan visitas de manera más frecuente al dentista (al menos cada 6 meses y control de la placa bacteriana), para evitar la aparición de caries y la pérdida prematura de piezas dentales. Esto se debe a que, al parecer, hay un aumento de la actividad de la colinesterasa en la saliva de pacientes con SS, lo que parece interferir con la actividad secretora glandular.

b. Tratamiento de la xeroftalmia.

Para sustituir la deficiencia lagrimal, se utilizan distintos preparados oftálmicos (metilcelulosa al 0,5\%, Tearisol, etc.); las lágrimas más eficaces son las lágrimas artificiales con hialuronato sódico. Es mejor utilizar lágrimas líquidas durante el día y en gel durante la noche. Sin embargo, el uso de lágrimas artificiales tiene sus consecuencias (derivado de ciertos componentes que poseen estas lágrimas: preservantes, estabilizantes, conservantes...), pudiendo producirse la sensibilización con picor e irritación del ojo (debe cambiarse a otro preparado). Se ha visto que en los pacientes con aAF positivos, se puede mejorar su secreción lagrimal con hidroxicloroquina.

Debe de tenerse ciertos cuidados generales, como protegerse del sol y viento con gafas adecuadas, control por oftalmología con la frecuencia necesaria...

En el caso de que haya filamentos mucoides u ojos pegajosos por las mañanas, puede estar indicado el tratamiento con un mucolítico (acetilcisteína).

Si la sequedad ocular es muy intensa, y no mejora con lo anteriormente citado, se puede intentar ocluir los canalículos lacrimales de manera temporal o permanente.

c. Tratamiento de otras xerosis.

Para la sequedad de piel y labios se pueden utilizar tratamientos tópicos adecuados. Para la sequedad vaginal existen geles lubricantes (también aceite de vit. E, cremas o cápsulas).

d. Tratamiento de las artralgias, mialgias y fatiga.

Las artralgias y mialgias son comunes en el SS, se pueden paliar las molestias con AINEs o analgésicos. Se ha visto que la hidroxicloroquina es útil, y puede ayudar a corregir parcialmente la hipergammaglobulinemia y reducir los anticuerpos IgG contra el 
antígeno La/SSB y la velocidad de sedimentación, además de aumentar los niveles de hemoglobina.

La fatiga es común en el SS, puede deberse al proceso inflamatorio en sí mismo, o bien a que haya alteraciones del sueño, por lo que además de los tratamientos anteriormente mencionados, es importante mantener medidas de higiene del sueño.

e. Tratamiento en casos de afectación sistémica.

La Hidroxicloroquina ( $200 \mathrm{mg} / \mathrm{dia}$ durante un año) es el tratamiento que se suele pautar para las complicaciones como artritis, fatiga y erupciones de la piel del SS. Ésta, reduce de forma significativa la concentración salival de mediadores inflamatorios como la IL-6 y de ácido hialurónico, así como la VSG, la PCR y las inmunoglobulinas en suero.

En los casos de afectación sistémica más graves, están indicados glucocorticoides u otros inmunosupresores (como la ciclofosfamida) o las gammaglobulinas (principalmente si hay afectación renal, afectación pulmonar grave, vasculitis sistémica, neuropatía periférica, anemia hemolítica o pericarditis). Las parestesias de la polineuropatía suelen responder al tratamiento con pregabalina.

Los esteroides pueden ser eficaces en el tratamiento de la nefritis intersticial crónica asociada a SS, antes de producirse la fibrosis irreversible. Las inmunoglobulinas intravenosas se han empleado profilácticamente en madres Ro positivas, para prevenir el bloqueo cardíaco neonatal.

En estudios recientes se ha visto que nuevas propuestas terapéuticas, enfocadas principalmente en el uso de agentes biológicos, pueden ser esenciales en el tratamiento de complicaciones graves, ampliando las opciones terapéuticas en el SSP ${ }^{16}$.

Se ha visto que el Infliximab y el Etanercept, no han demostrado eficacia significativa en el tratamiento del SS. En la actualidad se está trabajando en un estudio con Rituximab (estudio abierto de Fase II, tras un tratamiento con cortisona y antihistamínicos); se trata de un anticuerpo monoclonal anti-CD20 aprobado para el tratamiento de linfomas de tipo B y otras enfermedades autoinmunes; ha generado grandes expectativas, además de haber demostrado eficacia en linfomas B, pero un $25 \%$ de los pacientes tratados han desarrollado anticuerpos contra el Rituximab (HACAs), e incluso Enfermedad del Suero, lo que podría limitar su utilización en el tiempo (pues parece ser más eficaz en fases iniciales de la enfermedad, antes de producirse la destrucción glandular). En el caso del Ocrelizumab (Ac humanizado antiCD20) parece que tendrá la misma eficacia que Rituximab pero con menor inmunogenicidad, y el Belimumab (antagonista BAFF/BlyS), probablemente sea clave en el control de la hiperactividad de células B. Además, la similitud patogénica con el LES, sugiere que las terapias anti-IL, pueden ser de utilidad.

\section{Protocolo de vigilancia sanitaria específica en el Síndrome de Siögren}

Para poder aplicar este protocolo es necesario tener en cuenta múltiples factores, principalmente relacionados, por una parte, con la propia patología (sintomatología, evolución, tratamiento...), y por otra parte con su situación laboral (tipo de trabajo, condiciones de trabajo, etc.); sin embargo, resulta fundamental tener en cuenta también la actitud del paciente ante su enfermedad y la perspectiva ante su trabajo, tratamiento... De ahí la importancia de realizar una historia clínico-laboral lo más completa posible.

\section{Historia clínico-laboral en el Síndrome de Siögren}

\section{Anamnesis}

Habrá que realizar una correcta anamnesis laboral, incidiendo en ocupaciones anteriores y posible exposición a factores de riesgo previos, cara a plantearnos un diagnóstico diferencial (si el trabajador presenta sintomatología de SS pero todavía no ha sido diagnosticado), principalmente si ha trabajado previamente con exposición a productos químicos y/o riesgo biológico. 
En relación a su situación actual, habrá que definir de la manera más precisa posible, sus tareas y el modo de trabajo (definir la manera de realizar las tareas de su puesto), definir los riesgos e intentar señalar aquellos factores de riesgo que puedan incidir sobre la sintomatología que aqueje el trabajador.

En relación a lo anterior, hay que preguntar sobre la sintomatología actual, principalmente la que el paciente considere como más limitante, tanto para las actividades de su vida diaria (importante incidir sobre sus actividades de ocio y tiempo libre) como, principalmente, para su puesto de trabajo (para que nos sirva de guía, si luego hay que realizar una adaptación del puesto de trabajo, etc.).

\section{Exploración clínica}

Tras realizar la anamnesis, en la que se incluirá la sintomatología que refiera el trabajador con SS, se realizará la exploración clínica insistiendo, por una parte en la búsqueda de signos específicos del SS en base a la sintomatología descrita por el trabajador, y por otra parte, en la búsqueda de posibles signos que pudieran indicar otro tipo de complicaciones específicas del SS.

a. Inspección y palpación: se valorará si presenta ojos rojos, estado y coloración de piel y mucosas, por si hubiese lesiones (xerostomía, xerodermia, posible Raynaud, púrpura...), si se aprecia hipertrofia parotídea o si detectamos alguna adenomegalia/organomegalia a la palpación.

b. Auscultación: principalmente se valorará la auscultación pulmonar, en búsqueda de posibles signos de afectación pulmonar por el SS, pero no nos olvidaremos tampoco de descartar un posible roce pericárdico, etc.

c. Exploración neurológica y traumatológica básicas: valorar posible afectación neurológica, artralgias...

\section{Control biológico y estudios complementarios}

Dentro del control biológico, habrá que valorar los factores de riesgo específicos del puesto de trabajo:

- Será importante la realización de una exploración oftalmológica exhaustiva, mediante la valoración de la agudeza visual (AV), realización del Test de Schirmer, valoración de la córnea con una lámpara de hendidura tras tinción con fluoresceína. Si además trabaja con Pantallas de Visualización de Datos (PVD), habrá que controlar la tensión ocular. Seguramente será precisa la derivación del trabajador a un oftalmólogo para la realización de dicha exploración.

- Analíticamente, será importante la realización de una analítica de control, principalmente a controlar la serie blanca, descartar anemia, reactantes de fase aguda, hipergammaglobulinemia...Pero en caso de sospecha de complicaciones (ya descritas anteriormente), se podrían solicitar: enzimas cardíacas (si hubiese sospecha o antecedentes de pericarditis), enzimas hepáticos y/o pancreáticos (sospecha o antecedentes de afectación digestiva), controlar la función renal, solicitar sedimento de orina, y si el trabajador está expuesto a frío (trabajo en cámaras frigoríficas, etc. y sospechamos una posible crioglobulinemia), puede ser de gran utilidad la determinación analítica de crioglobulinas.

La mayoría de anticuerpos diagnósticos del SS y otros marcadores inmunológicos, se realizan en laboratorios especializados, pero en los casos en los que el trabajador no esté diagnosticado y tengamos una alta sospecha de SS, puede ser de interés la solicitud de FR, ANA y anticuerpos anti-Ro (SS-A) y anti-La (SS-B).

- A nivel pulmonar, habrá que realizar una espirometría forzada, y dependiendo del resultado, valorar si puede ser interesante la realización de una prueba de broncodilatación, test de difusión y/o test de la marcha (derivar a neumología para la 
realización de los mismos). Si disponemos de un pulsioxímetro podemos comprobar la saturación basal de oxígeno. ECG de control.

Las determinaciones/pruebas a realizar en el puesto de trabajo:

- Valorar y controlar el nivel de humedad ambiental, hacer especial hincapié en aquellos puestos con sistemas de aire acondicionado/climatización ambiental por aire, trabajos con exposición a temperaturas extrema (frío y calor intenso...), exposición a radiaciones (afectación ocular)...

- Valorar ergonómicamente el puesto de trabajo, principalmente en los trabajadores que trabajen con PVD, insistir en las recomendaciones para evitar la fatiga visual.

- Descartar el Síndrome de Edificio Enfermo ante la sospecha de un trabajador con clínica de SS, sin diagnosticar (sobre todo si se dan varios casos en el mismo centro).

- En aquellos trabajadores con SS expuestos a químicos, habrá que valorar la determinación de los Valores Límite Ambientales (VLA), tanto el VLA-ED (concentración media calculada de forma ponderada para una jornada estándar de $8 \mathrm{~h} / \mathrm{d}$ ), como el VLA-EC (concentración media calculada para cualquier periodo de $15 \mathrm{~min}$ a lo largo de toda la jornada laboral, excepto para aquellos agentes químicos que se especifique un periodo de referencia inferior).

\section{Vigilancia de la salud}

\section{Examen de Salud Inicial}

En el examen de salud inicial, además de realizar un examen específico en base a los riesgos del puesto de trabajo a los que esté sometido, y después de haber realizado la anamnesis (ya descrita anteriormente), se valorará si, en base a la sintomatología del paciente con Síndrome de Sjögren, deberemos considerar lo siguiente:

- Si debemos considerar al trabajador como especialmente sensible, en función de los factores de riesgo a los que esté expuesto en su puesto de trabajo; en este caso habrá que plantearse si es necesario realizar una adaptación del puesto de trabajo, además de realizar un control periódico de la vigilancia de la salud con periodicidad más breve.

- Si puede desempeñar su trabajo sin precisar una adaptación del puesto y programar la vigilancia de la salud con una periodicidad habitual.

- Si dada la sintomatología o complicaciones del Síndrome de Sjögren fuese incompatible con el desempeño de ese puesto de trabajo, considerándose como No apto para el mismo. En ese caso, se debería buscar un puesto de trabajo acorde a su sintomatología/complicaciones.

Si no hubiese la posibilidad de reubicar al trabajador en otro puesto de trabajo, a nivel legal existiría la posibilidad de una extinción laboral, ya que, cara a la valoración de la incapacidad permanente, se consideraría que las lesiones que padece el trabajador son previas a la incorporación al puesto de trabajo para el que presenta la no aptitud clínicolaboral.

\section{Examen de Salud Periódico}

En ellos, se valorará la posible aparición de nueva sintomatología en relación al SS, en base a la exploración física y pruebas complementarias.

Además, se hará especial hincapié en la sintomatología del SS primario:

- En los trabajadores que trabajen con Pantallas de Visualización de Datos y hayan presentado sintomatología ocular en relación a la xeroftalmia, se vigilará si el puesto de trabajo está ergonómicamente adaptado, si el trabajador cumple con los ejercicios para evitar la fatiga visual, se le insistirá en el uso de lágrima artificial, se valorará el nivel 
ambiental de humedad del puesto y se descartará que pueda presentar patología ocular que le incapacite temporalmente.

- En aquellos centros en los que se sospeche que pudiera haber un Síndrome del Edificio Enfermo, habrá que considerar al trabajador con SS como especialmente sensible, mientras continúe trabajando en ese centro.

- En los trabajadores con afectación pulmonar, y que estén expuestos a químicos ambientales, polvos en suspensión etc. Además de realizar los controles ambientales pertinentes para la valoración límite ambiental del tóxico, se deberá incidir en el uso de EPIs (mascarilla), y evitar la exposición (salir de la zona del tóxico a una cabina cerrada, etc.); en estos casos, habrá que realizar una vigilancia de la salud más estrecha, y considerar a estos trabajadores especialmente sensibles: habrá que intentar reubicarlos o adaptar el puesto de tal manera que se minimice la exposición a dicho riesgo prácticamente a cero (principalmente si se trata de productos irritantes pulmonares como formaldehído, etilendiamina... O todos aquellos que pudieran empeorar una posible fibrolsis pulmonar preexistente), cara a que dicha exposición no incida en la patología pulmonar derivada del S. Sjögren.

- En los trabajadores con antecedente de linfoma no Hodgkin (que se encuentren en remisión completa) y exposición a tóxicos inmuno-hematológicos ${ }^{17}$ : hidrocarburos aromáticos hidrogenados, hidrocarburos aromáticos policíclicos, determinados metales como el plomo (Pb), Arsénico (As), Mercurio (Hg), Cadmio (Cd), plaguicidas...Habrá que considerar apartar al trabajador de dichos tóxicos a nivel laboral o minimizar la exposición ambiental, prácticamente a niveles inexistentes.

- En los trabajadores con afectación neurológica, habrá que realizar una correcta valoración pues puede que presenten limitación para manejo de maquinaria peligrosa y/o conducción, trabajo en alturas...En relación a los químicos, se deberían de reubicar por la exposición a aquellos compuestos químicos cuya evidencia esté demostrada las neuronopatías ${ }^{17}$, un ejemplo: aluminio, arsénico, quinina, plomo, talio, mercurio y metimercurio...O minimizar la exposición ambiental a nivel prácticamente indetectables.

\section{Examen de salud previo a la incorporación del trabajo}

La realización de este tipo de reconocimientos médicos está muy discutida, ya que no se contempla en el Reglamento de los Servicios de Prevención. Sin embargo, siguen vigentes para aquellos puestos de trabajo en los que, por sus peculiaridades (ya sea porque son puestos de trabajo con requerimientos físico-psíquicos especiales, o puestos en los que se va estar expuesto a determinados riesgos) y posibles repercusiones en terceras personas, deben cumplirse una serie de requisitos de aptitud para poder desempeñarlos.

En estos casos, habrá que incidir en si la sintomatología y clínica que presente el paciente con SS es o no susceptible de aptitud en base a las demandas específicas del puesto de trabajo que se valore.

\section{Criterios de valoración médico-funcional de la capacidad laboral en el Síndrome de Sjögren}

En la revisión realizada sobre el Síndrome de Sjögren, no se ha encontrado ninguna clasificación ni estadiaje de gravedad de la enfermedad. Lo único encontrado han sido la diferencia entre Síndrome de Sjögren primario y secundario y si las manifestaciones son o no sistémicas. 
Al no haber una clasificación, se han tenido en cuenta los posibles factores agravantes en función de la sintomatología:

\begin{tabular}{ll}
\hline Úlceras corneales de repetición/ complicadas & Vasculitis sistémica, crioglobulinemia \\
Determinadas manifestaciones neuropsiquiátricas & Fibrosis pulmonar \\
Pancreatitis autoinmune & Posibles complicaciones por la disfunción tiroidea \\
Complicaciones nefrológicas: glomerulonefrítis, & $\begin{array}{l}\text { Determinadas formas de afectación neurológica: } \\
\text { nefritis túbulointersticial }\end{array}$ \\
\hline
\end{tabular}
Linfoma No Hodgkin tipo B

Para poder realizar una correcta valoración, habrá que tener en cuenta las posibles complicaciones del SS:

1. Linfomas no Hodgkin ${ }^{9}:$ Los factores pronósticos se han comentado anteriormente, la afectación y gravedad dependerá de la clínica, respuesta al tratamiento, estadio...

2. Afectación respiratoria: en función de la clínica (como el grado de disnea) y resultado de las distintas pruebas diagnósticas y funcionales.

i. Graduación de la disnea según la escala MRC:

1. Disnea grado 0 (ninguna): no hay disnea salvo con ejercicio intenso, etc.

2. Disnea grado 1 (ligera): nota disnea al caminar deprisa o subir una pendiente ligera...

3. Disnea grado 2 (moderada): debido a la disnea, camina más despacio en llano que las personas de su edad.

4. Disnea grado 3 (severa): tras caminar unos $100 \mathrm{~m}$ o algunos minutos, se detiene para respirar.

5. Disnea grado 4 (muy severo): disnea al vestirse/desvestirse, con mínimos esfuerzos.

3. Habrá que valorar si existe una posible afectación neurológica, a qué nivel, gravedad, posibilidad de recuperación, etc.

4. Úlceras corneales de repetición o complicada con perforación ocular u otro tipo de complicaciones.

5. Afectación nefrológica en función de la gravedad de una posible glomerulonefritis, nefritis tubulointersticial...Se valorará la creatinina, MDRD y Filtrado Glomerular, sedimento de orina...

6. Se valorará la existencia de crioglubulinemia u otras vasculitis sistémicas.

7. Otras complicaciones: pancreatitis autoinmune, pericarditis, disfunciones tiroideas...

\section{Grupos funcionales orientativos}

\section{Grado Funcional 0}

Pacientes diagnosticados de SS que se encuentran prácticamente asintomáticos o con sintomatología muy leve.

No existirán complicaciones: analítica y clínicamente no habrá alteraciones significativas, a nivel pulmonar presentará unos valores espirométricos dentro de la normalidad, a nivel gastrointestinal no habrá clínica o si la hay, serán molestias leves. A nivel oftalmológico no habrá patología, aunque puede presentar ojo rojo y precisar la utilización de lágrima artificial, puede presentar xerostomía sin complicaciones digestivas...

Conclusiones: no presentan limitaciones funcionales y pueden realizar una actividad laboral normalizada. 


\section{Grado Funcional 1}

Pacientes con sintomatología leve: puede presentar ojo rojo y problemas relacionados con la xeroftalmia, u otras xerosis. No habrá complicaciones significativas, si hubiese afectación pulmonar, sería leve, puede existir clínica de mialgias de carácter leve sin alteraciones significativas analíticamente (salvo las propias del Sjögren). Puede presentar queratitis de manera puntual, que requieran un periodo breve de IT hasta su curación. Otra sintomatología: mialgias, hiperreactividad bronquial que curse con sintomatología leve, alguna complicación leve tras alguna infección periodontal, afectación renal leve (filtrado glomerular entre 30 y $59 \mathrm{ml} / \mathrm{min}$ ), disfunción tiroidea que curse sin secuelas...

Conclusiones: pueden presentar alguna limitación, probablemente derivada del disconfort higiénico-ergonómico del puesto de trabajo, pero éstas no incapacitan para la realización de su trabajo. En algún caso puede ser precisa la incapacidad temporal, pero tras la estabilización, no quedarán secuelas o si quedan, son leves y no limitan para el desempeño del puesto de trabajo.

Recomendaciones preventivas: Como ya se ha mencionado anteriormente, habrá que incidir en el nivel de humedad ambiental, una correcta adaptación ergonómica del puesto de trabajo, recomendar pautas para evitar la fatiga visual, utilizar lágrimas artificiales y tener a disposición bebidas no azucaradas, insistir en la protección ocular. Insistir en las revisiones periódicas odontológicas.

\section{Grado Funcional 2}

Pacientes con sintomatología moderada en relación a que haya cursado con alguna complicación, subsidiarias en su mayoría de periodos de incapacidad temporal, pero que en muchos casos se mantenga algún tipo de secuela permanente.

Puede ser el caso de las úlceras corneales que precisarán una incapacidad temporal hasta que se curen (en el caso de una buena evolución, el GF2 sería únicamente para el periodo de IT), o si presentan una mala evolución y se complican; patología pulmonar que curse con una disnea grado 2 acompañada de una afectación moderada; si hubiese afectación renal, se tratará de una situación prediálisis (proteinuria $>300 \mathrm{mg} / 24$ h, filtrado glomerular entre 15 y $29 \mathrm{ml} / \mathrm{min} .$. ); afectación neurológica moderada pero que se estabilice; vasculitis que una vez pasada la fase aguda se estabilice...

Conclusiones: En general se tratará de complicaciones sistémicas que tras la estabilización posterior a la fase aguda, cursen con secuelas leve-moderadas que en la mayoría de los casos no incapacitarán para el desempeño del puesto de trabajo, pero que pueden cursas con discapacidad para actividades con requerimientos físicos de mediana y gran intensidad, exposición prolongada al frío (si existiera crioglobulinemia), o en el caso de la úlcera corneal, mientras no se cure la lesión, incapacitará de manera temporal para el trabajo con PVD, soldadura...Si hubiese afectación neurológica, habría que valorarla, probablemente presente una discapacidad para realizar determinadas tareas...

Recomendaciones preventivas: además de las ya mencionadas en relación al puesto de trabajo, habrá que incidir en las revisiones periódicas por oftalmología, y si procediese, por distintos especialistas dependiendo del tipo de complicación que presentara el trabajador.

\section{Grado Funcional 3}

En el Síndrome de Sjögren no es habitual valorar este grado, sólo se contemplará en aquellos casos en los que las complicaciones sistémicas sean manifiestas: afectación renal con sintomatología moderada-severa (proteinuria de $>1 \mathrm{gr} / \mathrm{d}$, filtrado glomerular entre 19 y $10 \mathrm{ml} / \mathrm{min} . .$.$) que puede precisar hemodiálisis o diálisis peritoneal, afectación pulmonar$ que curse con una disnea grado 3 o 4 acompañada de un déficit funcional severo o muy severo; afectación neurológica con sintomatología limitante a pesar del tratamiento (si lo hubiese). Linfoma no Hodgkin estadio I/II o estadios III/IV en los que se hubiese podido 
realizar un transplante alogénico (aunque serán pocos los casos...) y/o cursen con complicaciones leves-moderadas derivadas del trasplante (en estos casos si se concede una incapacidad permanente, será subsidiaria de revisión para poder valorar la evolución de la enfermedad, respuesta al tratamiento...).

Conclusiones: limitados para tareas con requerimientos físicos de intensidad leve, en gran parte de los casos se podrá valorar una limitación para la capacidad laboral, habrá que determinar, dependiendo de la afectación sistémica, si se trata de una incapacidad permanente absoluta o una incapacidad permanente total.

\section{Grado Funcional 4}

Será excepcional en un SS llegar a este grado funcional, pero puede tratarse del caso de un difícil control de las complicaciones derivadas del SS, como por ejemplo: enfermedad renal con sintomatología severa, a pesar incluso del tratamiento sustitutivo (Filtrado glomerular $<10 \mathrm{ml} / \mathrm{min} . .$. ); insuficiencia respiratoria crónica con grave deterioro del estado funcional; LNH estadío III/IV o estadíos I/II que hayan cursado con complicaciones severas postrasplante.

Conclusiones: capacidad laboral abolida en todas sus modalidades e incluso pueden precisar ayuda para las actividades de la vida diaria. Valorar la incapacidad permanente absoluta y si la gravedad fuese tal que precisara ayuda para las actividades de la vida diaria, habría que valorar la gran invalidez (Índice de Barthel y otras escalas).

\section{DISCUSIÓN}

El hecho de la dificultad diagnóstica en el Síndrome de Sjögren, en gran parte puede deberse a una falta de coordinación entre distintos servicios médicos ante el inicio de la sintomatología. No obstante, aun en aquellos casos en los que sí hay una buena comunicación interdisciplinar, es complicado el diagnóstico por la clínica, precisando otra serie de pruebas diagnósticas más invasivas.

Es importante un diagnóstico lo más precoz posible, cara a plantear un seguimiento estrecho de las posibles complicaciones. Sin embargo, ante la sospecha de un posible Sjögren, si la sintomatología es leve, muchos especialistas no se plantean, de entrada, la realización de una biopsia glandular salivar u otras pruebas medianamente invasivas; por eso, habría que plantearse si, ante una sintomatología inicial de carácter leve, compatible con la del SS, no estaría indicada la realización de una prueba invasiva con el fin de facilitar a posteriori un seguimiento más estrecho del paciente.

Además de las molestias que esta serie de pruebas diagnósticas (sialometría, sialografía parotídea, biopsia de glándula salivar...) puedan conllevar, habría que valorar si la relación coste/beneficio de las mismas justificaría la realización de las mismas ante una sintomatología de carácter leve.

Una vez instauradas las complicaciones sistémicas, hasta que no se dispuso la opción terapéutica mediante terapia biológica (Rituximab...), las posibilidades terapéuticas eran escasas, y en los casos de complicaciones sistémicas avanzadas, poco efectivas. Sin embargo, no hay que perder de vista que este tipo de tratamientos también tienen una serie de efectos secundarios o complicaciones, que aunque poco frecuentes, pueden ser graves. Por lo tanto, a pesar de un diagnóstico temprano, también se debería plantear el beneficio/ riesgo de la prescripción de este tipo de terapias como de primera línea terapéutica.

Por otra parte, el hecho de que la sintomatología inicial sea de carácter leve (y como se ha mencionado previamente, pocas veces diagnosticada en esa etapa), hace que a nivel preventivo no se puedan valorar las posibles complicaciones. Así, ante un trabajador con una sintomatología leve compatible con SS, se debería valorar con detenimiento la exposición a determinados factores de riesgo o condiciones de trabajo que puedan empeorar el Sjögren, y plantear un posible seguimiento más estrecho en cuanto a la vigilancia de la salud. 
El hecho de no tener en la literatura médica una relación entre los posibles riesgos que puedan afectar y/o empeorar al trabajador con Síndrome de Sjögren, tampoco facilita la labor preventiva en relación a la vigilancia de la salud en estos trabajadores.

Debido a esto, mediante este trabajo se ha intentando plantear un protocolo que englobe la mayoría de pacientes diagnosticados de SS; sin embargo, dada la diversidad de la sintomatología, resulta complicado poder realizar un protocolo de aplicación uniforme, debiéndose valorar cada caso por separado. A esto se añade, como anteriormente se ha mencionado, la necesidad de valorar los riesgos y características peculiares de cada puesto, para poder establecer, si procediera, las restricciones y/o precisión de una adaptación del puesto o reubicación laboral, o si fuese el caso, la necesidad de plantear una incapacidad permanente.

\section{CONCLUSIONES}

El síndrome de Sjögren está infradiagnosticado, por la dispersidad de la sintomatología que puede presentar y la no realización, a priori, de un correcto diagnóstico diferencial. Esto hace que en muchas ocasiones, cuando se diagnostica, la infiltración linfocitaria a nivel glandular sea avanzada, y ello conlleva que a nivel terapéutico sea complicado su manejo. No obstante, en relación a las últimas investigaciones con terapia biológica, se abre un nuevo camino en cuanto a las posibilidades terapéuticas del SS. De ahí que sea tan importante el correcto diagnóstico del Sjögren, principalmente porque en otros cuadros que cursen con síndrome seco, no está indicado este tipo de terapias (principalmente en el caso del tratamiento biológico con Rituximab, Ocrelizumab...).

La realización de un diagnóstico lo más precoz posible, hace que se pueda plantear un seguimiento más estrecho del paciente; así, se podrá realizar un screening precoz de las posibles complicaciones, cara a poder facilitar el seguimiento y manejo terapéutico de las mismas.

Lo mismo ocurre a nivel laboral. Así, el poder disponer de un protocolo de vigilancia de la salud específico para trabajadores con Síndrome de Sjögren, facilitará el planteamiento preventivo que anteriormente se menciona. Facilitará también el que se contemplen las posibles complicaciones y limitaciones que éstas puedan generarle al trabajador afecto de SS.

Por esa razón, tras estudiar este síndrome, se ha desarrollado un protocolo de vigilancia de la salud específico, en el que se han incluido los criterios de valoración de la capacidad laboral del trabajador afecto de SS. De esta manera, se pretende que dicho protocolo pueda servir como herramienta de trabajo en los trabajadores afectos de este síndrome.

No obstante, ante la variedad de factores de riesgo y peculiaridades de cada puesto de trabajo, para poder aplicarlo, primero será preciso adaptarlo a las necesidades específicas de cada puesto de trabajo, teniendo en cuenta las peculiaridades del mismo (factores de riesgo a los que esté sometido, condiciones de trabajo, actividad concreta...).

Por lo tanto, este protocolo no es más que una mera guía en la que poder apoyarse, pero no hay que olvidar que cada caso precisará una valoración individualizada tanto médica como laboral.

\section{REFERENCIAS BIBLIOGRÁFICAS}

1. Coll Daroca J. Síndrome de Sjögren. En: Farreras Rozman. Medicina Interna. 14 ed. Vol. 1. Sec. 7. Parte II: Enfermedades Sistémicas. Cap.149. Madrid: Harcourt; 2000. pp.1272-1273.

2. Juan Martín, J. El Médico Interactivo. Revisiones clínicas monográficas: Síndrome de Sjögren. Se consigue en: http://www.elmedicointeractivo.com/ap1/emiold/biblio/rbcn44.htm.

3. Sociedad Española de Reumatología. Síndrome de Sjögren. Se consigue en: http://www.ser.es/ ArchivosDESCARGABLES/Folletos/05.pdf. 
4. Asociación Española de Síndrome de Sjögren. Disponible en: http://aesjogren.org/?page_id=29. Acceso: febrero de 2013.

5. Cotran RS, Kumar V, Collins T. Robbins. Patología estructural y funcional. 6 ed. Cap. 7: Trastornos de la inmunidad. Madrid: McGraw-Hill-Interamericana; 2000. pp. 240-241.

6. Calvo Aranda E, Santiago Muñoz F. Síndrome de Sjögren. Oct.2011. Se consigue en: http://www.jano.es/ ficheros/sumarios/1/00/1775/53/1v00n1775a90034638pdf001.pdf.

7. Fitzpatrick TB, Johnson RA, Wolff K, Suurmond D.Atlas en color y sinopsis de dermatología clínica. 4 ed Sec. 16: Signos cutáneos de las enfermedades hematológicas. Crioglobulinemia. Madrid: McGraw-HillInteramericana; 2001. pp. 504-505.

8. Ramírez M, Ramos Casals M, Graus Ribas F. Afección del Sistema Nervioso Central en el síndrome de Sjögren Primario. Med Clin 2009, 133(5): 349-359.

9. Rabasa MP. Factores pronósticos en los linfomas: linfomas no Hodgkin y linfoma de Hodgkin. Anales de Servicio Navarro de Salud. Disponible en: http://www.cfnavarra.es/salud/anales/textos/vol24/suple1/ suple13a.html.

10. Institut Ferran. Síndrome de Sjögren. Disponible en: http://www.institutferran.org/sd_sjogren.htm. Acceso en febrero de 2013.

11. Silvestre FJ, Puente A, Bagán JV, Castell JV. Presencia de péptidos de fibronectina en la saliva de pacientes con Síndrome de Sjögren: un indicador potencial de la destrucción de las glándulas salivares. Medicina Oral, Patología Oral y Cirugía Bucal 2010, 15(3): 148-153.

12. Ferraz Amaro IA. Proteínas HHESB, TAU y WAVE como nuevos autoantígenos en el Síndrome de Sjögren. Rev Esp Reum 2003, 30(5): 185.

13. Arteaga MF, Machargo MV, Acosta E, Cózar Castellano I, Ferraz Amaro IA. Búsqueda de nuevos autoantígenos en el Síndrome de Sjögren. Reumatología Clínica 2005, 1 (4): 187-192.

14. Infante de la Torre JR, Durán Barquero C, García Bernardo L, Groiss Biuza J, Rayo Madrid JI, Serrano Vicente J, y col. Coexistencia de dos tipos de linfomas en una paciente con Síndrome de Sjögren. Utilidad de la PET-TAC. Rev Esp Med Nucl Imagen Mol 2012; 31(01): 28-30.

15. Díez Morrondo C, Lema Gontad JM, Álvarez Rivas N, Atanes Sandoval A, de Toro Santos FJ, Pinto Tasende JA, Galdoa F. Aspectos actuales del síndrome de Sjögren etiopatogenia, manifestaciones clínicas, diagnóstico y tratamiento. Seminarios de la Fund Esp Reum 2010, 11(2): 70-76.

16. Muñoz S, Brito Zerón MP, Castellanos JA, Belenguer R, Rosas Gómez de Salazar JC. Presente y futuro de las terapias biológicas en el Síndrome de Sjögren Primario. Rev SVR 2007, 2(3):41-46.

17. Klaassen CD, Watkins III JB. Manual de Toxicología, 5. ${ }^{a}$ Ed. Mexico DF: McGraw-Hill Interamericana; 2001.

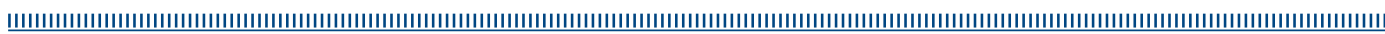

